\title{
A psicanálise não é a de sempre ${ }^{1}$
}

\author{
Rahel Boraks 2
}

Em primeiro lugar, quero agradecer à Comissão organizadora deste evento, pela gentileza do convite que muito me honra. Penso que é sempre enriquecedor estar entre colegas tendo oportunidade de compartilhar e trocar ideias que diariamente se fazem presentes em nosso fazer psicanalítico.

No momento que recebi estes dois instigantes escritos, busquei encontrar um tema que percorresse ambos. Algo que pudesse nos fazer trilhar pela tradição reinventada que é a demanda que nosso trabalho nos faz diariamente. Pensei que poderíamos conversar sobre a diversidade na especificidade um tema paradoxal que sublinha a esfera na qual nos movimentamos.

Neste mundo, no qual o homem não está mais contido em um globo e é convidado a viver no infinito, a psicanálise tem sido convocada a se rever continuamente e manter "teorizações flutuantes" . Um mundo, que infinito, deixa o homem à mercê de frequentes estados de agonia frente aos quais, passa a se utilizar do imediato e do globalizado, adquirindo frequentemente, uma vizinhança forçada com seres coexistentes de acaso, que momentânea e falsamente, parecem protege-lo da agonia, da solidão e do vazio que prevalece.

As mudanças que se observam no mundo contemporâneo são de tal modo profundas, que inauguram a necessidade de repensar alguns dos nossos pressupostos teóricos para manter a vitalidade do jogo que nossa experiência e nossas concepções nos convidam a

\footnotetext{
${ }^{1}$ Este trabalho foi apresentado em oficina sobre as plenárias no I Simpósio Bienal "O mesmo, o outro: Psicanálise em movimento" da Sociedade Brasileira de Psicanálise de São Paulo.

2 Analista Didata da Sociedade Brasileira de Psicanálise de São Paulo, docente do Instituto Durval Marcondes
} 
jogar. Penso que organizar este simpósio e convidar colegas a aprofundar nosso jogo, revela prontidão para sublinhar a dimensão inconsciente, por vezes, limitada ao sensorial ou ao clivado no homem que vive diante destes desafios.

Não podemos perder de vista o fato de que as várias teorias da psicanalise, são estórias sobre a estória de indivíduos e a diversidade destas estórias é expressão da riqueza, do alargamento e da abrangência da analisabilidade.

Cito Ana que afirma: “A psicanálise Contemporânea compreende diferentes áreas do funcionamento psíquico. Hoje, trabalhamos com pares que se tornam indissociáveiscomo pulsão/objeto e transferência/contratransferência-e com articulações entre o intrapsíquico e o intersubjetivo, o que implica novas posições do analista."

Bernardo destaca em paralelo:" Hoje a diversidade das práticas desenvolvidas a partir de uma abordagem psicanalítica para responder às diferentes formas de sofrimento humano mostra a riqueza de uma clínica de maior complexidade em seu alcance terapêutico e suas teorias explicativas.

Concordo com o fato de que "enfrentamos a necessidade de manter permanente abertura, enfatizando a expansão e abrangência do pensamento psicanalítico para além da clínica. As contribuições que a psicanálise pode oferecer em inúmeros campos culturais, sociais e a importância de estarmos preparados para estas solicitações se colocam como desafio." No entanto, penso ser importante destacar que este preparo, se dá na psicanálise encarnada, na clínica que possibilita a realização das transformações que podemos ajudar a alcançar em outros campos. É na clínica que vivenciamos transformações que se realizam com aquilo que nos é dado por nossos analisandos que vem nos procurar porque há algo errado com sua capacidade de transformação. Buscam análise porque foram incapazes por alguma razão, de criar algo suficientemente sustentador além daquilo que lhes foi dado para sua nutrição. É com essas experiências absolutamente singulares que nosso universo interno se expande. 
Essa expansão se dá com oscilações que envolvem momentos nos quais se busca reestabelecer ora, aliados primários, reconstruir de certo modo, a provisão primária, tratar do destino das primeiras impressões que tornam presente o passado em formas refiguradas, observar a maneira como se moldaram as primeiras impressões em função das necessidades ou apetites e do modo como se transformaram em expectativas, em buscas ou em outras formas que se fazem presentes na relação.

Outra demanda se dá, quando o analista busca restaurar o artista no paciente. Digo o artista, pois me refiro àquela parte do psiquismo que cria interesse e torna interessante, qualquer que tenha sido a provisão primária. Desta forma, a possibilidade de fazer uso da arte pessoal, promove o investimento em algo chamado vida ou experiência. Ocorre um trabalho que torna interessante o que está se dando na experiência e a curiosidade e $\mathrm{o}$ apetite permanecem e se mantem vivos, porque o interesse os sustenta.

Penso no entanto, que um alerta se faz necessário: assim como a ânsia de abrangência pode levar ao abalo de fundamentos absolutamente necessários. $\mathrm{O}$ atendimento rígido a estas sequencias ou observações, pode nos fazer cair em perigoso esquematismo. Para servir de exemplo tomo a questão edípica tão cara à psicanálise.

A clínica com crianças e adultos nos ensina repetidamente que a rivalidade impaciente, a pretensão de exclusividade, o desejo sensual e sexual, que são partes da cena edípica, se manifestam se puderam encontrar apoio na firmeza e saúde do casal parental. Este tem que estar em bom estado, ou seja, indestrutível. A possibilidade de lidar e conviver com a cena primária e a exclusão que ela impõe, é precedida por outra experiência que a antecede e que vai além do erótico ajudando a criança a deter seus impulsos incestuosos e seus desejos de domínio sobre cada um dos pais, além de ocupar-se com o cuidado do laço que teme possa se romper. Assim pode se dizer que há uma correlação entre a intensidade edípica e o estado do par parental. Há, um ponto que merece atenção de nossa parte: quando se mencionam estes pares ou quando se menciona a conduta de uma criança que mostra preferência pela mãe ou medo, quando este apego se revela frágil, não temos muito a dizer ou o que agregar. Surge imediatamente em nossa mente a 
questão Edípica com sua identidade caracterizada pela imobilidade. A movimentação teórica que alterna a compreensão teórica de lá para cá, que assinala diversas funções ou tempos, não chega a afetar a identidade destas questões dentro de nós. Entendemos do que se trata quando apenas mencionamos seus nomes.

Será que Édipo enquanto consequência de um complexo jogo, foi suficientemente pensado? Winnicott nos alerta:- quando um jogo não pode ser jogado profundamente, nos resta a adaptação. A necessidade de oposição que daria impulso ao necessário enfrentamento com o pai rival, amortece se o holding previamente necessitado carece de firmeza. O que resta para a criança, é a inibição, a submissão, o aprisionamento, pois os pais não estão prontos para que o brincar possa acontecer. A criança se instala nas fissuras parentais passando a manipular estas fissuras, para tirar algum proveito que inevitavelmente, se constitui patológico. Que não sejamos nós esta criança. Que possamos brincar profundamente com nossas experiências e com nossos conceitos para que aquilo que em nós estiver como barreira rígida, possa se tornar algo mais tênue que oscila e se enriquece com as mudanças que estamos vivendo.

É importante pensar nos matizes que restauram complexidades implícitas, em planos aparentemente muito simples. Para tanto, é importante ou melhor, imprescindível, incorporar em nossa experiência a singularidade que pode se desdobrar e proliferar, gerando um aprofundamento. É a partir disto que podemos dizer que a psicanálise não é a de sempre e que Winnicott com seu gradualismo, permite discernir infinitas matizes a cada passo. São transições inaudíveis, com as quais tenho convivido na minha clínica e as quais gostaria de compartilhar com vocês agora.

Parto de um pressuposto colocado por Winnicott ao longo de seus vários escritos: $\mathrm{O}$ homem nasce para ser e para que isto seja alcançado necessita do encontro. Assim o ego é este gesto, é busca, e realiza tropismo em busca do humano.

O que o impulsiona é a tendência inata ao amadurecimento, à busca de ser, de ter experiência de si e cada vez mais de si mesmo. 
Assim se pode afirmar que uma expressão paradoxal ao mesmo tempo precisa de Winnicott, propõe que estar só, implica a presença de alguém. Propõe que a presença acolhedora do outro permite que o indivíduo possa chegar a reconhecer os eventuais contextos faltosos e ou solitários, sem precisar negá-los de modo onipotente. Dito de outro modo, para chegar ao mundo, o ser humano precisa estar firmemente ancorado em contextos acolhedores. Esta base acolhedora permite que não ocorra a chegada repentina a um exterior que invade. Chegar desta maneira, causaria a necessidade de uma rápida adaptação de si e no lugar da subjetivação, surgiria um vazio.

Se isto ocorre, a irrupção enigmática do sujeito vazio se ancora no mundo mimeticamente e encobre agudos estados de agonia. Nesta realidade, na qual o homem está confrontado desde muito cedo, com contínuos desencontros, a temporalidade se estende, atravessando e desconsiderando ritmos naturais da vida, privando o sujeito de elementos fundamentais para que se organize um interior, base do mundo pessoal.

Não há tempo para a elaboração das perdas, nem espaço para os desinvestimentos. Tudo é trânsito veloz e as necessárias passagens internas e externas, se dão por saltos que muitas vezes, ignoram profundas fenda que impossibilitam uma apropriação em sentido pessoal e exigem uma potência/ maturidade, que ainda não foi naturalmente alcançada.

Penso ser interessante destacar a insistência de Winnicott no fato da mãe não intervir apenas para modular ou satisfazer a imperiosa exigência da pulsão, mas para auxiliar o surgimento da fantasia que reforça um nascer para dentro. $\mathrm{O}$ adentramento no mundo não coincide com o nascimento biológico, mas, tem a ver com a participação em relações de proximidade que protegem o indivíduo do que poderia ser uma situação de grande sofrimento em torno de agonias impensáveis.

Neste sentido quero propor um fato que tenho observado na experiência clínica com certa frequência. Refiro-me presença de estados de agonia que em muitos aspectos diferem dos estados de desamparo. Tenho observado que o desamparo é um estado que se refere à conquista do intersubjetivo e é da relação com que ele surge. Por outro lado, 
a agonia, está ligada e surge do Co subjetivo, momento no qual, prevalece a necessidade de estar em e a ausência deste elemento fundamental tem a ver com um ente vivo, real, que não chega de fato, a ser presença.

A palavra desamparo, em princípio pressupõe dois seres; o amparado e o que ampara. Em estados primitivos, este amparo não é sentido como tal e sim, experenciado como segurança, tranquilidade e bem-estar. Embriões do desamparo inicialmente enraizados na corporeidade, necessitam de sustentação para alcançar figuração psíquica. Estes embriões se degeneram quando o sujeito chega demasiadamente exposto ao exterior, transformando-se em agonia e enlouquecimento.

É um desafio e uma inquietação para nós psicanalistas, investigar o que representa esta guinada de perspectiva e o quanto estes estados de agonia, não mais vistos como desamparo, afetam os sujeitos, suas relações e nossa clínica.

Sabemos que a continuidade do sendo, é condição sine- qua- non para o desenvolvimento do sentimento de si e que um fracasso do ambiente em garantir os meios para que se estruture um padrão pessoal de ser, do qual o sujeito se aposse, pode resultar em uma proliferação de seres capazes de complexidade técnica, mas, para os quais, a possibilidade de estabelecer relações sempre coloca em risco suas esferas protetoras que são o rastro necessário destas primeiras vivências em.

Perdas precoces das relações primeiras, dificultam a aquisição da existência de si e do outro e vários psicanalistas tem sido enfáticos em descrever o quanto relações objetais defeituosas ou traumatogênicas ficam clivadas (Roussillon 2014), e passam a ser atuadas ou repetidas como forma de busca do que permaneceu ausente de si. Quando nos deparamos com estes aspectos petificados que estão fora da mente e fora do psiquismo, a dimensão do entre, não existe. O desamparo que implica algo entre, já não está ao alcance do indivíduo. É a agonia que prevalece. O que se apresenta, é um indivíduo para quem a efração traumática se dá à custa do empobrecimento do conjunto da vida psíquica, apresentando um quadro clínico que muitas vezes, se aproxima da 
compulsão à repetição, do vazio e da necessidade de constantemente destruir o sonho do analista para que na ruptura, possa ganhar alguma notícia confiável de si.

A adaptação materna às necessidades do bebê e o cuidado na apresentação do mundo, é a chave para conseguir sentir e estar livre participando da realidade. No entanto, o início não é algo que acontece entre sujeito e objeto, é algo que nasce de uma intimidade que cria um espaço sustentado, que impedirá que a criança se depare com a agonia de estar sendo jogada numa exterioridade radical e ter que enfrentar uma solidão não visitada. A perda ou inexistência desta função acolhedora primária, não terá como resultado vivencia de desamparo e sim, um estado agônico de contínuo e permanente aniquilamento das possibilidades de constituição de si ou uma falsificação em, geralmente estabelecida a partir da mente, na qual o sujeito passa viver aprisionado.

Para finalizar penso ser importante uma observação: Tentar buscar consenso muitas vezes, não passa do desejo de criar fantasias de normalidade. É importante sermos capazes de conviver com discordâncias sem que seja preciso concordar. Esperar a concordância torna empobrecidas as trocas que nos ajudam a conhecer diferenças e obstaculizam a necessidade de permanente abertura para com a singularidades.

Postas estas questões fica evidente que a especificidade da psicanálise hoje já não se refere a um modelo clínico único e sim ao trabalho e sim ao trabalho psicanalítico que precisa recorrer a diversos dispositivos práticos e vários modelos teóricos de tal modo, que a formação, a experiência de análise e reanálise do analista cobram toda sua importância.

\section{Referências}

ARMONY, N. ( 2013) Quem tem medo do salto mortal? Sobre amparo e desamparo IN: O Homen transicional São Paulo: Zagodoni 
MACHADO, T.A.P. (2018) A Psicanálise e suas Clínicas: Avanços e Aberturas. Apresentado no; I Simpósio Bienal da SBPSP,O Mesmo, o Outro - Psicanálise em Movimento.

MIZRAHI, G,B. ( 2010) O ambiente facilitador em Winnicott: uma alternativa para o desamparo e a regulação na experiência subjetiva in: A vida criativa em Winnicott: Rio de Janeiro, Garamond.

ROUSSILLON, R. (1999) O Trauma narcísico Identitário e sua Transferência. In Revista Brasileira de Psicanálise Volume 48, n.3. 2014.

TANIS, B. (2018) A psicanálise e suas clínicas. Apresentado no; I Simpósio Bienal da SBPSP,O Mesmo, o Outro - Psicanálise em Movimento.

WINNICOTT, D,W. (1969) A experiência mãe-bebê de mutualidade.In Explorações Psicanalíticas. Porto Alegre: Artes Médicas.

WINNICOTT,D.W. (1960) Distorção do ego em termos de verdadeiro e falso self in : O ambiente e os processos de maturação Porto Alegre: Artes Médicas, 1982.

WINNICOTT, D.W. ( 1969) O conceito de trauma em relação ao desenvolvimento do indivíduo dentro da família. In Explorações Psicanalíticas. Porto Alegre: Artes Médicas, 1994. 